\title{
No simple menu for sustainable food production and consumption
}

\author{
Shabbir H. Gheewala ${ }^{1,2}$ (D) $\cdot$ Niels Jungbluth $^{3} \cdot$ Bruno Notarnicola $^{4} \cdot$ Brad Ridoutt $^{5,6} \cdot$ Hayo van der Werf ${ }^{7}$
}

Received: 12 June 2020 / Accepted: 18 June 2020 / Published online: 13 July 2020

(C) Springer-Verlag GmbH Germany, part of Springer Nature 2020

\section{Introduction}

Sustainable food production and consumption are very important parts of the so-called Sustainable Development Goals (SDGs) adopted by the member states of the United Nations. Life cycle assessment (LCA) as an assessment tool is very well-suited to help towards this. The scope of food LCA studies covers not only the processing stage but also upstream (i.e., raw material production - agriculture, livestock, fisheries and aquaculture, and packaging production) and downstream (i.e., distribution, consumption, and waste disposal) activities including related transport in all stages. The life cycle impact assessment results covering multiple impacts in quantitative terms facilitate the identification of hotspots (i.e., the main life cycle stage and activities causing significant impacts) to derive strategies for life cycle management to improve the environmental performance of product and promote the shift towards sustainable agriculture and food production systems including more sustainable food consumption patterns via environmental certification and labelling schemes.

Responsible Editor: Matthias Finkbeiner

Shabbir H. Gheewala

shabbirg@hotmail.com; shabbir_g@jgsee.kmutt.ac.th

1 The Joint Graduate School of Energy and Environment, King Mongkut's University of Technology Thonburi, Bangkok, Thailand

2 Center of Excellence on Energy Technology and Environment, PERDO, Ministry of Higher Education, Science, Research and Innovation, Bangkok, Thailand

3 ESU-services Ltd., 8200 Schaffhausen, Switzerland

4 Ionian Department of Law, Economics and Environment, University of Bari Aldo Moro, Bari, Italy

5 Commonwealth Scientific and Industrial Research Organisation (CSIRO), Clayton South, Victoria 3169, Australia

6 Department of Agricultural Economics, University of the Free State, Bloemfontein 9300, South Africa

7 UMR 1069 Soil, Agro and Hydrosystems, INRAE, Institut Agro, 35000 Rennes, France
LCAs of studies on agriculture and food have come a long way with over 3000 articles being published until April 2020. Based on a Scopus search with "life cycle assessment" AND "agriculture" OR "food", the number of articles showed a more than threefold increase from around 120 in 2010 and 2011 to over 400 in 2018 and 2019. Although the publications have been predominantly from the USA and Europe, it is also interesting to note that over this period, the contributions from Asia tripled from about $7 \%$ to over $20 \%$. This might to some extent reflect the increase in research interest in this field in Asia (Gheewala 2012; Gheewala et al. 2017), culminating in the LCA Food 2018 conference being organized in Thailand. It was the 11th in a series of biannual conferences starting in 1996, attracting about 200 participants from 25 countries with around 160 oral and 40 poster presentations. As done in previous Food LCA Conferences (Nemecek et al. 2016; Notarnicola et al. 2016; van der Werf et al. 2014; Notarnicola et al. 2012), papers addressing some of the key and cutting-edge issues in sustainable food consumption and production were selected from this conference and a few more added from the normal flow of submissions to the International Journal of Life Cycle Assessment to form this special issue comprising a total of 15 articles.

\section{The papers of this special issue}

Although case studies formed a very important part of the presentations at the conference, many of the studies presented the state-of-the-art in impact assessment methodologies. The topics covered in the selected papers include many current areas of research. The inclusion of nutritional aspects of food, not only in the assessment of food products but also in comparative assessments (via the functional unit), has been one of the largely discussed issues in food-related LCAs. This is also an important consideration when studying sustainable diets, which is directly linked to SDG 2 (zero hunger), although nutrition is essential to the success of all SDGs (Blesh et al. 2019; Fanzo 2019). A link is also drawn to the assessment of food loss and waste under SDG 12 (responsible consumption and production) (UN 2019). 


\section{Diets and nutrition}

As mentioned above, sustainable diets are a very important cross-cutting goal that needs research. However, like most LCA studies, this also requires a very large amount of data that can be a challenge to collect. Top-down studies using data from the Food and Agriculture Organization (FAO) of the United Nations combined with available national data could be a good start at making reasonable estimates. Such an approach was suggested by Heller et al. (2019) and implemented for studying the transitions to sustainable diets in developing countries using the cases of Vietnam and Kenya (Heller et al. 2019). The increase in the consumption of meat in Vietnam over the last decade and the consistent use of beef and dairy products in Kenya were responsible for a large part of the greenhouse gas (GHG) emissions. These were also responsible for a significant water scarcity footprint in both countries in addition to the increased imports of wheat and rice in Kenya from water-stressed regions. The data limitations of the food balance sheets from FAO, for example, the omission of food waste, which is an important aspect, must be recognized. Despite the data limitations and also some limitations in methods, the results were helpful in pointing to the hotspots in a transition to sustainable diets leading to supporting information for policy interventions. A consumption-based perspective was also useful to complement the productionbased national accounting that is usually carried out. The study also referred to the traditional trade-offs between human development and socio-economic standards with environmental protection goals, which are important to recognize in policy-making. The interaction among SDGs is an important aspect to be considered for creating synergies among goals when formulating policies.

One of the limitations of the above study was the noninclusion of food loss and waste in the evaluation of diets. This aspect, covered under SDG 12.3 which aims at halving food waste by 2030 , is a very important area of research. After all, the food that is lost or wasted carries the same environmental burdens from production as the food that is consumed. According to FAO, at a global level, about one-third of all food is wasted or lost throughout the supply chain (Gustavsson et al. 2011). Although the waste management hierarchy recommended to be followed would give priority to preventing food waste and reusing it, commercial interests may often prefer recycling via anaerobic digestion over redistribution (Vázquez-Rowe et al. 2019). In terms of resource efficiency, however, this is not an appropriate solution as also for humanistic and ethical concerns. Food is a basic human need and serves esthetic, social, and cultural needs over and above providing sustenance. To account for this, it is important to also integrate the nutritional and economic value of the food in decision-making towards food waste management in addition to mass. The study of Vázquez-Rowe et al. (2019) thus looked at the nutritional and economic costs of food loss and waste across the supply chain using the case of Spain. To this end, an indicator, the nutritional cost footprint, was developed using linear programming and optimization tools combined with nutritional and economic variables. The study attempted to overcome the disconnect between food loss and waste reduction policies that are typically focused on the consumer and climate action policies that are mainly focused on agriculture and farming. By looking at the entire supply chain and recommending strategies based both on food categories and supply stages, using an indicator including both nutritional and economic aspects, category-specific recommendations could be provided to reduce food loss and waste that would be useful for policy-makers as well as waste managers and other related stakeholders.

The two studies discussed above (Heller et al. 2019; Vázquez-Rowe et al. 2019) follow a series of studies that have been conducted at a dietary level. Other recent review studies, for example, by González-García et al. (2018) and Hallström et al. (2018), have also included the consideration of nutritional quality in environmental assessment at the dietary level which marks a shift from mass-based LCAs in the past. However, it is also important to link diet-level studies to the commodity level so that actionable strategies can be generated for food producers to reduce their environmental impacts even though they do not really control consumption patterns (McAuliffe et al. 2020). This is particularly important because a majority of the environmental burdens generated in agrifood systems are typically generated at the farm. It points to the direction of future research on multiple food groups and production systems, which should include nutritional aspects in the functional unit to account for the effects of nutrients on the overall dietary quality. The issue of functional unit in food LCAs has long been a topic of discussion and research because food fulfills several functions; even though nutrition can be seen as the primary biological function, food also provides pleasure, cultural value, satiety, and so on. Taking into account all these "secondary" functions is difficult, and even including the primary function of nutrition has not been too straightforward. The most common mass-based functional unit can somewhat be justified when comparing diets which may have similar nutritional value but with different components (Sonesson et al. 2017); however, this may not usually be the case when disparate diets or food types are considered. More sophisticated units have used a single nutritional aspect such as calorie- or protein-based functional units (Heller et al. 2013). Even more complex functional units have been developed based on nutrient profiling (e.g., Arsenault et al. 2012; Drewnowski and Fulgoni III, 2008). Weidema and Stylianou (2019) go a step further in considering not only the nutritional value in the functional unit but also the impact of food on human health. They discuss that for nutritional value to be included in the functional unit, it must be an obligatory 
property. However, except for functional foods and for cases where there is insufficient accessibility of food, desirable nutrients are not obligatory properties in the sense the customers do not necessarily make a decision between competing alternatives based on them. Rather they serve as positioning properties for competing alternatives similar to price. They argue that satiety (feeling of fullness) is a more relevant measure of function; people will decide based on satiety when they will require an additional snack or the next meal. A framework is provided which includes nutritional measures in the functional unit in terms of satiety as well as in the calculation of impacts in the form of marginal influence of a specific food on the human health impact of the overall diet.

\section{Land use, carbon accounting, and biodiversity}

Within the agriculture phase, land use and land use change (LULUC) is a large contributor to the GHG balance and within it, soil organic carbon (SOC) is a major contributor. Agricultural practices that influence SOC by reducing losses or increasing sequestration can thus play an important role in GHG mitigation. SOC is also important from the point of view of soil functions providing crucial ecosystem services such as nutrient cycling, erosion resistance, and water filtering. Methodological developments in LCA over the last two decades have resulted in a conceptual framework for the impact of land use on soil quality (Milà i Canals et al. 2007; Koellner et al. 2013). However, there is still no scientific consensus on the method to evaluate LULUC within LCA. Bessou et al. (2019) attempt to address this gap by reviewing the currently available methods for assessing SOC in LCA and testing them on various case studies to evaluate their suitability for application in agricultural LCAs and their sensitivity to changes in land use and agricultural practices. The IPCC (stock difference) method (IPCC 2006) is chosen as it is one of the most widely used methods in LCA. The Müller-Wenk and Brandão (2010) method is chosen as currently the only method that connects the climate change impact with the conceptual land use framework mentioned before. The dynamic LCA method of Levasseur et al. (2012) is chosen to account for the variation in climate change impact based on the timing of GHG emission or sequestration. The study showed that from the perspective of LCA practitioners, the IPCC method was the easiest method to apply. The method of Müller-Wenk and Brandão (2010), though more complicated, could still be integrated into the LCA software as an independent characterization method and could then be easy to implement. Dynamic LCA was the most difficult to apply considering the extensive data requirements for modeling soil carbon stock dynamics. All methods were associated with their own sets of uncertainties. Finally, a stepwise approach was suggested for application. The easiest to apply in the absence of detailed data would be the IPCC tier 1 approach followed by the tier 2 approach when more detailed data is available. Care should be taken to understand the subjectivity involved when interpreting the results.

The study of Sevenster et al. (2019) looks at the long-term SOC changes in the LCA of agricultural products. It recognizes the necessity of including SOC changes in LCA following especially the recent ISO 14067 (ISO 2018) which prescribes that GHG emissions and removals due to SOC changes from land use should be included in carbon footprints. SOC changes under constant land use in Australia are modeled using the agricultural production systems simulator (APSIM). The SOC changes are modeled at the level of agro-ecological regions to allow for modeling within a relatively homogeneous system in terms of crops, rotations, climate, and soils. The results can contribute to use in LCA as well as life cycle inventory. It was seen that even in the absence of recent change in land use or land management, the GHG emissions or removals due to SOC change can have a significant effect on the overall carbon footprint of crops. The study thus emphasizes once again the importance of the modeling of SOC changes and the methodology development. As for the study of Bessou et al. (2019), this study also advises caution when interpreting the results from this due to the significant uncertainties and variabilities involved in the calculations.

The importance of using dynamic LCA in GHG accounting was also studied by Albers et al. (2019) who looked at dynamic full carbon accounting for evaluating prospective bioenergy scenarios. GHG reduction options often focus on the use of biogenic carbon sources for energy to displace fossil-based carbon dioxide emissions. The reason is that the uptake of atmospheric carbon dioxide via photosynthesis during the growth of plants (biogenic carbon source) can "balance" the carbon dioxide released when the biogenic carbon is combusted for energy, the so-called carbon neutrality. However, this balance has been debated in the scientific community especially for the case of forest-based bioenergy which has long rotation lengths and thus long sequestration periods (Searchinger et al. 2009; Haberl et al. 2012). Conventional LCAs tend to be static and steady state, not accounting for the time effects of emissions (or sequestrations), considering all emissions (or sequestrations) across the life cycle to occur at once regardless of where (for GHG emissions at least) and when they occur. Long-term sequestration of carbon in the forest biomass, which could extend over decades may, however, warrant consideration of temporary carbon storage. Also, the effect of modeling the biomass growth (forest) before harvest or after harvest is different. So Albers et al. (2019) studied the difference in results of modeling choices (before harvest/historic vs. after harvest/future) on the carbon sequestration in forestry for bioenergy vis-à-vis the greenhouse gas 
balance using a dynamic LCA approach. A partial equilibrium model was used combining prospective energy system analysis with biogenic carbon modeling to assess the time-sensitive climate consequences of an energy policy scenario with fossil and biogenic carbon accounting. The dynamic carbon balance modeled the carbon uptake into biomass via photosynthesis (fixation) and carbon release via decay considering time aspects. Carbon release via combustion was considered as instantaneous. The results show that the time of forest growth really matters; a historic perspective (carbon sequestration before harvest) resulted in a temporal carbon credit/benefit whereas a future perspective (carbon sequestration after harvest) resulted in a temporal carbon debt/loss. This is quite different from the carbon neutrality assumption that has traditionally been used. A historic perspective would be applied in practice for managed forestry because the forest has been grown for the purpose of bioenergy. A future perspective on the other hand would be applied in practice for harvesting of unmanaged forests if they are replanted after the harvesting.

The impacts of land use are not limited to greenhouse gas emissions though a lot of studies tend to focus on this. Land areas provide important ecosystem services (provision of food and freshwater, erosion regulation, water purification, recreation, and ecotourism) which may be disturbed when the land is used or transformed (Millennium Ecosystem Assessment 2005). Thus, this impact must be addressed within LCA; one of the methods being developed for this is LANCA® (Land Use Indicator Value Calculation in Life Cycle Assessment). This method uses indicators for erosion resistance, mechanical filtration, physicochemical filtration, groundwater regeneration, and biotic production which cover ecosystem services such as erosion regulation, soil formation, water purification, fresh water, water regulation, climate regulation, primary production, and food (Bos et al. 2020). The characterization factors describe ecosystem quality differences and are computed as the difference between the quality indicator for the reference land use type and that for the actual land use. The WWF ecoregions are used to characterize the natural situation before anthropogenic interference. However, as the soil parameters and climatic conditions are very sitespecific, the need for regionalized characterization factors is also recognized. An attempt is made by Bos et al. (2020) for developing such regionalized characterization factors using a geographic information system (GIS)-based platform. Developing such factors helps identify areas where a particular land use will result in lower environmental impacts than other areas. This framework is very useful for integrating land use impact assessment in LCA studies. From an LCA practitioner point of view, it has been recommended that developing a single index would be even more useful.

Another important impact of land use is that on biodiversity. Many impact assessment methods have been developed over the years to characterize the effects of land use and land use change on biodiversity. Many studies have been conducted and further refined, for example, by Koellner and Scholz $(2007,2008)$ and deBaan et al. (2013a,b, 2015) who developed characterization factors for different land use categories and different ecoregions. The updated characterization factors provided by Chaudhary et al. (2015) for each land use category and ecoregion were tentatively recommended by the United Nations Environment Programme (UNEP) and the Society of Environmental Toxicology and Chemistry (SETAC) Life Cycle Initiative. More recently, Chaudhary and Brooks (2018) proposed further revised characterization factors based on land use category and ecoregion under three levels of land use intensity. The study by Hayashi (2020) points to a serious limitation of this method in not being able to distinguish between conventional and environmentally friendly agriculture systems especially at the specific crop field level. This may work against the promotion of sustainable management practices in agriculture as its advantages for biodiversity will not be apparent. This was brought out by Hayashi's study which found it difficult to show a difference in the classification of land use intensity for conventional and environmentally friendly agriculture at the ecoregion level. Another example was the lack of difference in the biodiversity impact assessment between conventional management and integrated pest management. A need was therefore identified for clarifying the application of characterization factors derived from ecological zoning and land use classification to the assessment of agricultural production systems at the field scale. There was also a suggestion to consider biodiversity indicators focused on species diversity such as Shannon and Simpson indices in addition to species richness. A proposal was made to construct biodiversity indicators based on management practices at the field and farm level and to establish appropriate aggregation procedures consistent with measurement scales. Finally, it was concluded that looking at the biodiversity impacts of management practices was more important for promoting a transition to sustainable agriculture systems than assessing biodiversity impacts of land use and land use change.

\section{Assessing pesticide impacts}

One of the important practices in agricultural management systems is the application of pesticides which has serious implications on human and ecosystem health which are modeled in LCAs. As with many of the other impact categories in LCA, the modeling of pesticides has also largely been developed in and thus focuses more on temperate climates. Tropical climates, however, are more productive on the account of having a warm climate throughout the year. This climatic condition is also favorable for the occurrence of pests which require some form of treatment to maintain crop yields and quality. 
Application of pesticides is a common way to combat the effect of pests on crops. It has been observed quite often that farmers in tropical countries are not very well-trained in the application of pesticides, are less aware of the risks, and tend to practice excessive use, thus increasing the human and environmental impacts. As the crop production systems and pesticide application regimes in tropical climates are quite different from those in temperate climates, the modeling of the impact of pesticides on human and environmental health developed mainly based on temperate conditions needs to be adjusted accordingly. The key factors to be taken into account are the environmental characteristics of the tropical conditions along with agricultural practices and farmers' behavior (Gentil et al. 2019). To accommodate this, the existing databases need to be extended to include tropical crop characteristics and cropping/farm management practices as well as soil and climate types. The models also need to be adjusted to include the differences in partitioning of pesticides among the different environmental compartments based on the tropical conditions (e.g., late application of pesticides before harvest) resulting in differences in pesticide uptake pathways.

To avoid the damage of pesticides to human and ecosystem health described above, organic farming, which prohibits the use of synthetic pesticides (and chemical fertilizers) is promoted as a sustainable agricultural practice. However, for various crops, a lower yield has been observed for organic farming as compared with conventional farming (Seufert et al. 2012). This is also the case for vineyard systems, which were studied by Renaud-Gentié et al. (2019). However, despite reduction in synthetic chemicals, organic viticulture in certain situations still uses higher amounts of sulfur, copper, and diesel for synthetic herbicides and fungicides. Moreover, organic viticulture may be more sensitive to interannual variations of intervention frequency than conventional viticulture. The study of RenaudGentié et al. (2019) identified the main pathways for environmental improvements in organic viticulture by increasing energy efficiency of the farm machinery, reducing the impacts of harmful chemicals by appropriate choice of substitutes and dose management.

\section{Accounting and data}

The importance of a consumption-based approach in addition to a production-based national accounting approach in policymaking was highlighted before, for the study of sustainable diets by Heller et al. (2019). This was focused on also by the study of Chandrakumar et al. (2019) for the greenhouse gas emission for the case of New Zealand to support climate policy-making. Under the Kyoto Protocol and the more recent Paris Agreement, GHG emissions are accounted for based on the country where they are released (national inventory accounting); this is the production-based approach. However, this approach is often criticized because it does not account for emissions associated with imports of goods and services or international air and maritime transport. A perverse outcome of this approach has been the relocation of heavy industries (polluting industries) to countries with lax regulations; the effect is the so-called carbon leakage. The solution to this is consumption-based accounting, which allocates the emissions to the final consumers of goods and services. This approach, however, is associated with practical difficulties in accounting requiring sophisticated methods and a lot of data. The development of multi-regional input-output (MRIO) analysis and several large-scale MRIO databases has helped to support the implementation of the consumptionbased approach. Chandrakumar et al. (2019) used both the production- and consumption-based approaches to account for the GHG emissions in New Zealand. Their study revealed that different sectors dominate the GHG accounting when the two approaches are used. Also, a consumption-based approach is more suitable for developing consumer-oriented policies which can support a transition to low-GHG consumption practices. They also identified a third approach, shared producer and consumer responsibility, where GHG mitigation responsibilities are shared by the different actors in a value chain based on the benefit that each obtains using value added as a proxy.

The huge data requirement for conducting LCAs has been a challenge, especially for the agriculture and food sector. Various attempts made to deal with this challenge include the development of MRIO databases mentioned above. Another related issue is that the development and refinement of life cycle impact assessment categories necessitate the upgrading of the existing datasets to support the additional data requirements thereof. Avadí et al. (2019) made a first attempt to aggregate and standardize seafood-related datasets in the ecoinvent database. Representation datasets of the capture, aquaculture, and industrial processing of seafood in South America were constructed. Infrastructure included construction, use, maintenance, and end-of-life of the fishing vessels. The inventory items were based on the existing literature in the fishing and aquaculture sectors in South America. The existence of European data on aquaculture was recognized, as was the lack of data on Asian aquaculture as well as the commonly used integrated aquaculture systems (e.g., rice-fish, livestock-fish, integrated multi-trophic aquaculture). Additional data requirements are anticipated with the inclusion of new impact categories such as biotic depletion, degradation of the marine environment due to nano-, micro-, and macro-plastics accumulation in the ocean or damage to seafloor.

\section{Case studies}

Apart from the methodological considerations in addressing the challenges of LCA in sustainable consumption and 
production of food, the applications of LCA are also very important to consider. One of the classic utilization of LCA is for comparative assessments and identification of environmental hotspots for suggesting improvement options. The study by Silalertruksa and Gheewala (2019) evaluates the sugarcane biorefinery system in Thailand looking at various configurations for food (sugar), biofuel (ethanol and electricity), and biochemical (polylactic acid) production. Various combinations of these alternate products are evaluated using the eco-efficiency indicator which combines life cycle assessment (environmental indicator) and gross value added (economic indicator). The study looks at the environmental and economic indicators separately as well as in the combined form as eco-efficiency helping to identify not only improvement options but also the pathway towards strong sustainability by improving both the environmental and economic aspects rather than only looking at improving the ratio (ecoefficiency), which can still result in a trade-off between the two aspects.

Another such application of LCA for comparative assessment was carried out by de Figueiredo Tavares and Mourad (2020) who analyzed various methods of coffee preparation. Coffee is currently being produced in 60 countries in the equatorial region, with Brazil being the largest producer and second largest consumer. The life cycle environmental impacts of coffee have been widely studied, and as with most agricultural products, the agriculture stage is identified as the most impactful due to the application of agrochemicals and also the use of water for irrigation. However, the packaging and energy used in the preparation of the beverage can also have significant impacts. The study of de Figueiredo Tavares and Mourad (2020) revealed that the impacts from coffee preparation depended on the beverage concentration, the ratio of packaging mass per volume prepared, and the type of process for beverage extraction. The quantities of non-degradable packaging waste going to landfill can be very different; single-serve pods method using paper sachets associated convenience for individual consumption with low environmental impact. The information generated by the study could be useful for the environmentally aware consumer as well as for the public policy related to environmental education, recycling, and circular economy.

One of the fundamental applications of LCA has been that for eco-design. The study of Rouault et al. (2019) focused on this application for the case of vineyard management. As farmers are the main stakeholders in the agriculture stage, having the "field" knowledge and also being the final decision-makers, it would be quite interesting and important to have their involvement in the eco-design of farming systems. Rouault et al. (2019) combined LCA and a participatory approach for the eco-design of vineyard management via conducting workshops for winegrowers and extension officers. The main challenges in making the LCA results usable for participatory eco-design were to make the LCA results understandable for the participants, enabling easy manipulation of LCI data and modularity of LCA results, and producing live LCA results during the collective design process. The proposed approach can also be extended to other agricultural systems.

\section{Conclusion}

This Special Issue covers some of the very topical issues associated with the sustainable consumption and production of food. Methodological issues with assessment of carbon storage, soil organic carbon, dynamic carbon accounting, impacts associated with land use, pesticide toxicity, and biodiversity are discussed. The issues of appropriate functional units for assessment of food supply chains, sustainable diets, and food loss and waste are also covered. Also, some case studies illustrating the application of LCA to agriculture and food systems are included to provide a comprehensive coverage of issues.

\section{References}

Albers A, Collet P, Benoist A, Hélias A. Back to the future: dynamic full carbon accounting applied to prospective bioenergy scenarios. Int $\mathrm{J}$ Life Cycle Assess (2019). (this issue) https://doi.org/10.1007/ s11367-019-01695-7

Arsenault JE, Fulgoni VL III, Hersey JC, Muth MK (2012) A novel approach to selecting and weighting nutrients for nutrient profiling of foods and diets. J Acad Nutr Diet 112(12):1968-1975

Avadí A, Vázquez-Rowe I, Symeonidis A, Moreno-Ruiz E (2019) First series of seafood datasets in ecoinvent: setting the pace for future development. Int J Life Cycle Assess . (this issue) https://doi.org/10. 1007/s11367-019-01659-x

Bessou C, Tailleur A, Godard C, Gac A., de la Cour J.L., Boissy J., Mischler P., Caldeira-Pires A., Benoist A. Accounting for soil organic carbon role in land use contribution to climate change in agricultural LCA: which methods? Which impacts? Int J Life Cycle Assess (2019). (this issue) https://doi.org/10.1007/s11367-01901713-8

Blesh J, Hoey L, Jones AD, Friedmann H, Perfecto I (2019) Development pathways toward "zero hunger". World Dev 118:1-14. https://doi. org/10.1016/j.worlddev.2019.02.004

Bos U, Maier SD, Horn R, Leistner P, Finkbeiner M A GIS based method to calculate regionalized land use characterization factors for life cycle impact assessment using LANCA®. Int J Life Cycle Assess (2020). (this issue) https://doi.org/10.1007/s11367-020-01730-y

Chandrakumar C, McLaren SJ, Malik A et al. Understanding New Zealand's consumption-based greenhouse gas emissions: an application of multi-regional input-output analysis. Int J Life Cycle Assess (2019). (this issue) https://doi.org/10.1007/s11367-01901673-z

Chaudhary A, Brooks T (2018) Land use intensity-specific global characterization factors to assess product biodiversity footprints. Environ Sci Technol 52:5094-5104. https://doi.org/10.1021/acs.est. $7 \mathrm{~b} 05570$ 
Chaudhary A, Verones F, de Baan L, Hellweg S (2015) Quantifying land use impacts on biodiversity: combining species-area models and vulnerability indicators. Environ Sci Technol 49:9987-9995. https://doi.org/10.1021/acs.est.5b02507

de Baan L, Alkemade R, Koellner T (2013a) Land use impacts on biodiversity in LCA: a global approach. Int J Life Cycle Assess 18:1216 1230. https://doi.org/10.1007/s11367-012-0412-0

de Baan L, Curran M, Rondinini C, Visconti P, Hellweg S, Koellner T (2015) High-resolution assessment of land use impacts on biodiversity in life cycle assessment using species habitat suitability models. Environ Sci Technol 49:2237-2244. https://doi.org/10.1021/ es504380t

de Baan L, Mutel CL, Curran M, Hellweg S, Koellner T (2013b) Land use in life cycle assessment: global characterization factors based on regional and global potential species extinction. Environ Sci Technol 47:9281-9290. https://doi.org/10.1021/es400592q

de Figueiredo Tavares MP, Mourad AL. Coffee beverage preparation by different methods from an environmental perspective. Int $\mathrm{J}$ Life Cycle Assess (2020). (this issue) https://doi.org/10.1007/s11367019-01719-2

Drewnowski A, Fulgoni VL III (2008) Nutrient profiling of foods: creating a nutrient-rich food index. Nutr Rev 66(1):23-39

Fanzo J (2019) Healthy and sustainable diets and food systems: the key to achieving sustainable development goal 2? Food ethics 4:159-174

Gentil C, Fantke P, Mottes C, Basset-Mens C Challenges and ways forward in pesticide emission and toxicity characterization modeling for tropical conditions. Int J Life Cycle Assess (2019). (this issue) https://doi.org/10.1007/s11367-019-01685-9

Gheewala SH (2012) Challenges for LCA in the agri-food sector, perspectives from Thailand and Southeast Asia, Proceedings of the LCA Food 2012, Saint Malo, France, 02-04 October 2012

Gheewala SH, Silalertruksa T, Malakul P, Prapaspongsa T (2017) Promoting sustainability in emerging economies via life cycle thinking. Int J Life Cycle Assess 22:1641-1643

González-García S, Esteve-Llorens X, Moreira MT, Feijoo G (2018) Carbon footprint and nutritional quality of different human dietary choices. Sci Total Environ 644:77-94

Gustavsson J, Cederberg C, Sonesson U, Van Otterdijk R, Meybeck A (2011) Global food losses and food waste; extent, causes and prevention. Swedish Institute for Food and Biotechnology (SIK), Gothenburg (Sweden), and FAO. Rome, Italy

Haberl H, Sprinz D, Bonazountas M, Cocco P, Desaubies Y, Henze M, Hertel O, Johnson RK, Kastrup U, Laconte P, Lange E, Novak P, Paavola J, Reenberg A, van den Hove S, Vermeire T, Wadhams P, Searchinger T (2012) Correcting a fundamental error in greenhouse gas accounting related to bioenergy. Energy Policy 45:18-23

Hallström E, Davis J, Woodhouse A, Sonesson U (2018) Using dietary quality scores to assess sustainability of food products and human diets: a systematic review. Ecol Indic 93:219-230

Hayashi K. Inconsistencies between regional- and field-scale biodiversity indicators within life cycle assessment: the case of rice production systems in Japan. Int J Life Cycle Assess (2020). (this issue) https:// doi.org/10.1007/s11367-020-01749-1

Heller MC, Keoleian GA, Willett WC (2013) Toward a life cycle-based, diet-level framework for food environmental impact and nutritional quality assessment: a critical review. Environ Sci Technol 47(22): 12632-12647

Heller MC, Walchale A, Heard BR, Hoey L, Khoury CK, de Haan S, Burra DD, Duong TT, Osiemo J, Trinh TH, Jones AD Environmental analyses to inform transitions to sustainable diets in developing countries: case studies for Vietnam and Kenya. Int J Life Cycle Assess (2019). (this issue) https://doi.org/10.1007/s11367$019-01656-0$

IPCC (2006) Guidelines for national greenhouse gas inventories. Vol 4 Agriculture, Forestry and Other Land Use. WMO/UNEP. http:// www.ipcc-nggip.iges.or.jp/public/2006gl/index.html
Koellner T, de Baan L, Beck T, Brandão M, Civit B, Margni M, i Canals LM, Saad R, de Souza DM, Müller-Wenk R (2013) UNEPSETAC guideline on global land use impact assessment on biodiversity and ecosystem services in LCA. Int J Life Cycle Assess 18(6):1188 1202

Koellner T, Scholz R (2007) Assessment of land use impacts on the natural environment. Part 1: an analytical framework for pure land occupation and land use change. Int J Life Cycle Assess 12:16-23. https://doi.org/10.1065/lca2006.12.292.1

Koellner T, Scholz R (2008) Assessment of land use impacts on the natural environment. Part 2: generic characterization factors for local species diversity in Central Europe. Int J Life Cycle Assess 13:3248. https://doi.org/10.1065/lca2006.12.292.2

Levasseur A, Lesage P, Margni M, Brandão M, Samson S (2012) Assessing temporary carbon sequestration and storage projects through land use, land-use change and forestry: comparison of dynamic life cycle assessment with ton-year approaches. Climate Change 115(3-4):759-776

McAuliffe GA, Takahashi T, Lee MRF (2020) Applications of nutritional functional units in commodity-level life cycle assessment (LCA) of agri-food systems. Int J Life Cycle Assess 25:208-221

Milà i Canals LM, Bauer C, Depestele J, Dubreuil A, Knuchel RF et al (2007) Key elements in a framework for land use impact assessment within LCA. Int J Life Cycle Assess 12(1):5-15

Millennium Ecosystem Assessment (2005) Ecosystems and human wellbeing: synthesis. A Report of the Millennium Ecosystem Assessment. The Millennium Ecosystem Assessment series. Island Press, Washington, DC

Müller-Wenk R, Brandão M (2010) Climatic impact of land use in LCA - carbon transfers between vegetation/soil and air. Int J Life Cycle Assess 15(2):172-182

Nemecek T, Jungbluth N, Milà i Canals L et al (2016) Environmental impacts of food consumption and nutrition: where are we and what is next? Int J Life Cycle Assess 21(5):607-620

Notarnicola B, Curran MA, Hayashi K et al (2012) Progress in working towards a more sustainable agri-food industry. J Clean Prod 28:1-8

Notarnicola B, Sala S, Anton A et al (2016) The role of life cycle assessment in supporting sustainable agri-food systems: a review of the challenges. J Clean Prod 140:399-409

Renaud-Gentié C, Dieu V, Thiollet-Scholtus M, Mérot A Addressing organic viticulture environmental burdens by better understanding interannual impact variations. Int J Life Cycle Assess (2019). (this issue) https://doi.org/10.1007/s11367-019-01694-8

Rouault A, Perrin A, Renaud-Gentié C, Julien S., Jourjon F. Using LCA in a participatory eco-design approach in agriculture: the example of vineyard management. Int J Life Cycle Assess (2019). (this issue) https://doi.org/10.1007/s11367-019-01684-w

Searchinger TD, Hamburg SP, Melillo J, Chameides W, Havlik P, Kammen DM, Likens GE, Lubowski RN, Obersteiner M, Oppenheimer M, Philip Robertson G, Schlesinger WH, David Tilman G (2009) Fixing a critical climate accounting error. Sci 326(5952):527-528

Seufert V, Ramankutty N, Foley JA (2012) Comparing the yields of organic and conventional agriculture. Nature 485:229-232

Sevenster M, Luo Z, Eady S, Grant T Including long-term soil organic carbon changes in life cycle assessment of agricultural products. Int J Life Cycle Assess (2019). (this issue) https://doi.org/10.1007/ s11367-019-01660-4

Silalertruksa T, Gheewala SH. Competitive use of sugarcane for food, fuel, and biochemical through the environmental and economic factors. Int J Life Cycle Assess (2019). (this issue) https://doi.org/10. 1007/s11367-019-01664-0

Sonesson U, Davis J, Flysjö A, Gustavsson J, Witthöft C (2017) Protein quality as functional unit - a methodological framework for inclusion in life cycle assessment of food. J Clean Prod 140:470-478 
UN (2019) Sustainable development goal 12 - ensure sustainable consumption and production patterns. United Nations. Retrieved from: https://sustainabledevelopment.un.org/sdg 12 .

van der Werf HMG, Garnett T, Corson MS, Hayashi K, Huisingh D, Cederberg C (2014) Towards eco-efficient agriculture and food systems: theory, praxis and future challenges. J Clean Prod 73:1-9

Vázquez-Rowe I, Laso J, Margallo M, Garcia-Herrero I., Hoehn D., Amo-Setién F., Bala A., Abajas R., Sarabia C., Durá M.J., Fullana-i-Palmer P., Aldaco R. Food loss and waste metrics: a proposed nutritional cost footprint linking linear programming and life cycle assessment. Int J Life Cycle Assess (2019). (this issue) https:// doi.org/10.1007/s11367-019-01655-1

Weidema BP, Stylianou KS. Nutrition in the life cycle assessment of foods - function or impact?. Int J Life Cycle Assess (2019). (this issue) https://doi.org/10.1007/s11367-019-01658-y

Publisher's note Springer Nature remains neutral with regard to jurisdictional claims in published maps and institutional affiliations. 